\section{The importance of figural relationships between target and mask}

JOSEPH B. HELLIGE, DAVID A. WALSH, VIRGINIA W. LAWRENCE, and PAMELA J. COX University of Southern California Los Angeles, California 90007

Gummerman, Hill, and Chastain (1974) suggest that figural characteristics of the mask are unimportant in determining the course of backward recognition masking in vision. This conclusion is potentially very important because it contradicts several recent models of various aspects of visual information processing (e.g., Estes, 1975; Smith, Haviland, Reder, Brownell, \& Adams, 1976; Turvey, 1973). The present note provides a critical examination of the Gummerman et al. conclusion and presents additional demonstration data using the Gummerman et al. paradigm that indicates that figural relationships between target and mask can, indeed, be important determinants of the amount of backward masking.

Gummerman et al. employed a Landolt $\mathrm{C}$ with the opening in either the top or the bottom as the target. Each of three masks consisted of Xs placed in the visual field surrounding the target. A no-overlap mask consisted only of these surrounding Xs, a partial-overlap mask contained an additional $X$ overlapping the target but oriented so as not to block the opening, and a total-overlap mask had the additional $\mathrm{X}$ oriented so that it blocked the top and bottom openings in the target. When the target and mask were presented simultaneously in the same viewing field, recognition of the location of the target opening was quite good with both the no- and partial-overlap masks and at chance performance with the total-overlap mask. However, at all positive stimulus onset asynchronies (SOAs), the three masks were equally disruptive of target recognition. From these results, Gummerman et al. conclude that the mask interrupts processing of the target so that figural characteristics of the mask are unimportant in determining the amount of backward masking. Furthermore, the authors conclude that the results argue against a model of backward recognition masking that proposes that the target and mask are integrated into a single preperceptual image, because such an integration model would predict that the

Requests for additional information about the data reported in this paper should be sent to Joseph B. Hellige, Department of Psychology, University of Southern California, University Park, Los Angeles, California 90007 . The data collection referred to in this paper was supported in part by an NIMH research grant (MH 27116-01) awarded to Joseph B. Hellige and an NIA research grant (AG 00521-01) awarded to David A. Walsh. effectiveness of each mask would be determined by its ability to disrupt target recognition when the two are presented simultaneously (cf. Haber, 1970).

The conclusions reached by Gummerman et al. (1974) are, we believe, inappropriate for several reasons. The logic of the Gummerman et al. arguments rests in the finding that the three types of mask produce different amounts of masking at an SOA of 0 msec while producing the same amount of masking at all larger SOA values. The masks used by Gummerman et al. clearly meet the 0 -msec SOA criterion when the target and mask are presented together in the same viewing field, so that no luminance summation is possible. However, both those who favor an integration explanation of masking and those who conclude that a masking stimulus can interrupt processing of the target maintain that, at least for SOAs of about $50 \mathrm{msec}$ or less, target and mask luminances can be summed, producing a type of integration that is a result of energy relationships between the target and mask fields (e.g., Eriksen, 1966; Eriksen \& Rohrbaugh, 1970; Massaro, 1975; Spencer \& Shuntich, 1970; Turvey, 1973). It is therefore possible that, at short SOAs greater than $0 \mathrm{msec}$, luminance summation would make all of the masks used by Gummerman et al. equally effective.

In the Gummerman et al. experiment, both the target and the mask were $50 \mathrm{msec}$ in duration and $102 \mathrm{~cd} / \mathrm{m}^{2}$ in luminance, resulting in very high total energy levels. The shortest nonzero SOA employed was $50 \mathrm{msec}$. Given the resulting energy levels, and the fact that there was no interstimulus interval between the target and mask at $50 \mathrm{msec}$ SOA, it is possible that Gummerman et al. were obtaining luminance summation at that SOA (cf. Turvey, 1973). Indeed, target identification was near chance with all three masks. Unfortunately, at the next longest SOA, $100 \mathrm{msec}$, target recognition had reached asymptote with all three masks. Given these considerations, it cannot be concluded from the Gummerman et al. results that backward masking can be exclusively accounted for by interruption mechanisms or that figural characteristics of the mask are unimportant. It is clearly necessary to use energy levels and SOAs that allow for the possible separation of luminance summation from other masking mechanisms.

To demonstrate the strength of these arguments, 10 subjects were given eight trials at 0 -msec SOA in each of six conditions defined by the orthogonal combination of three types of mask similar to those used by Gummerman et al. with two presentation procedures-whether the target and mask were on the same slide (i.e., no luminance summation) or on two different slides in different viewing fields (i.e., allowing luminance summation). The target was a 


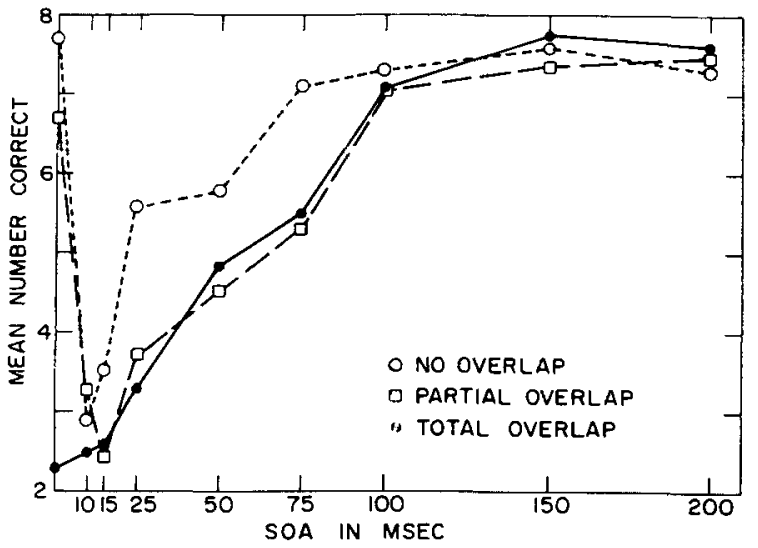

Figure 1. Mean number of correct responses, from a maximum of eight, as a function of SOA, with type of masking stimulus as the parameter. Chance is two items correct.

Landolt $C$ with the opening in the top, bottom, right, or left. Duration and intensity of both target and mask fields were $10 \mathrm{msec}$ and $120 \mathrm{~cd} / \mathrm{m}^{2}$, respectively. When the target and mask were on a single slide, the mean number of correct target recognitions was $7.3,6.7$, and 1.6 for the no-, partial-, and totaloverlap masks, respectively. These results are very similar to the 0 -msec SOA pattern reported by Gummerman et al. However, when the target and mask were presented simultaneously, but in two different viewing fields, the mean number of correct target recognitions was $2.2,1.5$, and 2.6 for the no-, partial-, and total-overlap masks, respectively. That is, performance was at chance (2.0) for all three types of mask. Therefore, it is quite possible that luminance summation can account for the absence of figural relationship effects at nonzero SOAs in the Gummerman et al. experiment.

With these considerations in mind, a second demonstration experiment was conducted using the same stimuli as the first. In an attempt to separate luminance summation from other masking mechanisms, SOAs of 0 (same slide), 10, 15, 25, 50, 75, 100 , 150 , and $200 \mathrm{msec}$ were examined for each of 10 subjects. Figure 1 shows the mean number of correct responses (from a maximum of eight per subject) for each of the SOA and masking stimulus combinations. The results at the 0 -msec SOA are as expected from the results of Gummerman et al. and from the earlier demonstration. At SOAs of 10 and $15 \mathrm{msec}$, it appears that luminance summation operates so that all three masks lead to chance identification of the target. Note that these results are similar to the 50-msec SOA results reported by Gummerman et al. and, as noted earlier, it is quite possible that because of the higher energy levels used by Gummerman et al. luminance summation in their experiment extended over larger SOA values than in the present demonstration.

Interestingly, at SOAs of 25,50 , and $75 \mathrm{msec}$ in the present demonstration, the target and mask luminances do not appear to be summed in the same manner as at shorter SOAs. Each of the three types of mask continued to disrupt target recognition at these SOAs, but the three masks were no longer equally effective. Rather, the masks which overlapped the target led to a lower level of target recognition than did the no-overlap mask. As Gummerman et al. (1974) argue, if the masking stimulus disrupts target identification at these SOAs by interrupting processing of the target (i.e., by replacing the entire preperceptual image of the target with a preperceptual image of the mask), then figural relationships between target and mask should be unimportant. Therefore, this notion of holistic interruption as expressed by Gummerman et al. and by several others (e.g., Massaro, 1975; Weisstein \& Haber, 1965) cannot be used to explain masking at SOAs of 25,50 , and $75 \mathrm{msec}$ in the present demonstration and cannot be the only mechanism of masking.

It is also apparent from the present demonstrations that, contrary to the conclusion of Gummerman et al., the figural relationships of target and mask are important determinants of the amount of masking. However, the nature of such effects depends on the extent of luminance summation, on SOA, and thereby on the range of masking mechanisms which are allowed to operate within a particular experimental design.

\section{REFERENCES}

Eriksen, C. W. Temporal luminance summation effects in backward and forward masking. Perception \& Psychophysics. 1966. 1. $87-92$.

Eriksen, C. W., \& Rohrbaugh, J. Visual masking in multielement displays. Journal of Experimental Psychology, 1970 , 83. $147-154$.

Estes, W. K. Memory, perception, and decision in letter identitication. In R. L. Solso (Ed.), Information processing and cognition: The Loyola symposium. Hillsdale. N.J: Lawrence Erlbaum Associates, 1975.

Gummerman, K.. Hill, G. A., \& Chastain, G. The unimportance of figural characteristics of visual noise masks. Journal of Experimental Psychology, 1974, 103, 820-822.

HABER, R. N. Note on how to choose a visual noise mask. Psychological Bulletin, 1970, 74, 373-376.

MASSARO, D. W. Experimental psychology and information processing. Chicago: Rand McNally, 1975.

SPEnCER. T.. \& Shuntich, R. Evidence for an interruption theory of backward masking. Journal of Experimental Psychol. ogy, 1970, 85, 198-203.

Smith, E. E.. Haviland, S. E., Reder, L. M., Brownell, H., \& ADAMS, N. When preparation tails: Disruptive effects of prior information on perceptual recognition. Journal of Experimental Psychology: Human Perception and Ferformance, 1976. 2. 151-161.

Turvey, M. T. On peripheral and central processes in vision: Inferences from an information processing analysis of masking with patterned stimuli. Psychological Review, 1973, 80, 1-52.

Weisstein. N., \& HABER, R. N. A U-shaped backward masking function in vision. Psychonomic Science, 1965, 2, 75-76.

(Received for publication December 24, 1976.) 